\title{
ДИНАМИКА ЗАПАСА СОСНЯКОВ ПО ТИПАМ ЛЕСА
}

(по данным J. Ilvessalo из книги А. К. Каяндера о лесах Южной Финляндии)

Мазуркин Петр Матвеевич

доктор технических наук, профессор, академик ЕАЕ, РАE и РАEН Поволжский государственный технологический университет, г. Йошкар-Ола

\section{DYNAMICS OF PINE FORESTS ACCORDING TO FOREST TYPES}

(according to J. Ilvessalo from A.K. Kayander's book about the woods of the Southern Finland)

\section{Mazurkin Peter Matveevich}

Doctor of Engineering Science, Academician of RANS, member of EANS, Volga State University of Technology, Yoshkar-Ola, Russia, E-mail: kaf po@mail.ru

Аннотация. Проанализированы выявленные устойчивыми закономерностями количественные данные Ilvessalo из брошюры А.К. Каяндера по типам леса и доказан волновой характер колебательной адаптации древостоя к лесной почве. Показано, что в типизации лесов нужна иерархия типа «функция - конструкция - параметры». Для создания действенной конструкции системы «древостой $\leftrightarrow$ почва» нужна последовательность формирования «компоненты состав - структура - конструкция». Функционирование древостоев показал Г.Ф. Морозов, а состав типов леса структурно оформил В.Н. Сукачев. Но недоставало параметризации, что и выполнил системно А.К. Каяндер. Это и позволило в статье дать математические модели.

\begin{abstract}
The quantitative data of Ilvessalo revealed by steady regularities from A.K. Kayander's brochure on types of the wood are analysed and wave nature of oscillatory adaptation of a forest stand to the forest soil is proved. It is shown that in typification of the woods the hierarchy like "function - a design - parameters" is necessary. For creation of an effective design of system "a forest stand $\leftrightarrow$ the soil" is necessary sequence of formation "components - composition - structure construction". G.F. Morozov showed functioning of forest stands, and the structure of types of the wood was issued structurally by V. N. Sukachyov. But lacked the parameterization that execute the system A.K. Kayander. It also allowed to give mathematical models in article.
\end{abstract}

Ключевые слова: типы леса, таблица хода роста, динамика запаса, закономерности Keywords: wood types, table of a course of growth, dynamics of stock, regularity

Введение. Большой известностью в зарубежных странах пользовалось учение о типах леса финского ученого А.К. Каяндера. В Финляндии оно имело не только теоретическое значение, но широко использовано при устройстве лесов. Основным признаком типа леса А.К. Каяндеру считал напочвенный покров [8]. Он допускал, что один и тот же тип леса может встречаться на разных почвах и, наоборот, на одной почве могут быть разные типы леса [2].

Цель статьи - проанализировать данные Ilvessalo, приведенные в брошюре А.К. Каяндера [3], и идентификацией устойчивых законов [5, 6] доказать волновой характер колебательной адаптации древостоя к лесной почве.

По словам учёного [3, с.10]: «Анализы почв показали, что почвы, отнесенные к I бонитету, содержат в большем количестве $\mathrm{P}_{2} \mathrm{O}_{5}, \mathrm{CaO}, \mathrm{MgO}, \mathrm{K}_{2} \mathrm{O}$ и $\mathrm{Na}_{2} \mathrm{O}$, чем почвы $\mathrm{V}$ бонитета, ... почти равномерное повышение от низших к 
высшим бонитетам». К сожалению, информационные технологии [1] пытаются адаптировать современные вычислительные возможности компьютеров к эвристическим уровням прошлого неавтоматизированного мышления, которые и поныне преобладают в лесной науке. В [1] явно виден старый системный подход с попытками перечисления «всех» элементов и факторов. Но при этом применяются линейные модели закона «неуклонного роста» СССР или «равномерного повышения» у А.К. Каяндера. А динамическая типология [4] пытается увеличить количество учитываемых факторов и при этом не проясняет главного - комплексного (функционального, конструктивного и параметрического) количественного представления о лесе.

Принимая концепцию динамической типологии, вначале нужно разобраться с типизацией лесов естественного происхождения, выполненного А.К. Каяндером. В начале XX века большинство систематиков не учитывали предостережения Ч. Дарвина об односторонности классификационных исследований. Следуя учению Дарвина, Каяндер все же не избежал ошибки Линнея, и старался создать линейную классификационную схему по типам леса.

Деля факторы на первичные и вторичные, А.К. Каяндер всё, что ныне относят к динамической типологии, считал просто случайностями [3, с.27-29]. Но его обзор данных измерений разных авторов, хотя они и сильно сгруппированы и поэтому их статистическая ценность недостаточно высока, имеет ныне сравнительную научную значимость. В начале XX века лесные массивы Южной Финляндии и российского Севера были естественного происхождения. За 100 лет после него сосняки в самой Финляндии изменились и стали полностью окультуренными. А в России ныне они вторичны и даже многократно видоизменены, причем полностью расстроены по возрастной структуре. Нормальные формы древостоев вырублены.

Однако наука всегда идет от простого к сложному. Поэтому вначале нужно понять закономерности поведения древостоев и почвы под ними по прошлым измерениям. Желательно было бы получить первичные данные измерений по 241 пробной площади и анализу ствола 241 модельной сосны господствующего класса роста [3, с. 34]. Но в нашем распоряжении имеются только сгруппированные по типам леса и классам возраста через 10 лет исходные данные в виде таблицы хода роста сосняков из южной половины Финляндии 1916-1918 гг.

Очевидно, что выявленные закономерности позволят математически обрабатывать и массивы первичных данных измерений из разных архивов и личных библиотек таксаторов.

Концепция идентификации поведения леса. Заметим, - разными авторами измерения проводились над деревьями и древостоями, а не леса как экосистемы. Почву А.К. Каяндер рассматривал в целом для Южной Финляндии. Поэтому вначале придется моделировать параметры сосняков по таблице хода роста, затем - параметры лесной почвы в зависимости от типов леса, и только после этого совместить показатели древостоев и почвы. В статье дается первая группа устойчивых статистических моделей по параметрам древостоев. 
Если по М.М. Орлову древостой есть фабрика по производству кругляка, причем он является основным компонентом леса как экосистемы, то лес содержит представителей многих царств природы (минералы, вирусы, бактерии, микроорганизмы, растения, животные). Процесс функционирования древостоя, а тем более леса, невозможно изучать без выявления устойчивых математических закономерностей динамики поведения.

Поэтому нужна иерархия типа «функция - конструкция - параметры». Однако для создания действенной конструкции какой-то системы, в нашем случае «древостой $\leftrightarrow$ почва», всегда нужна последовательность формирования «компоненты - состав - структура - конструкция». Функционирование древостоев подробно показал Г.Ф. Морозов. Состав и частично общую структуру леса после Г.Ф. Морозова по типам оформил В.Н. Сукачев. Но им обоим недоставало параметризации, т.е. 3-го уровня, чтобы окончательно создать конструкцию.

Известно, что конструкция мертва и останется не функционирующей структурой, если не будет третьей подсистемы - «параметры». Триаду «функции - конструкция - параметры» удачно разработал А.К. Каяндер. Тем самым он заложил основы современных лесных технологий (способы и средства) и лесной статистики Финляндии и Швеции. Но до идентификации леса как целостной экосистемы еще очень и очень далеко.

Исходные данные. В таблице 1 [3, с.34-35] четко представлена «конструкция - параметры», а описание функций по типам леса дано в брошюре. Поэтому нужно параметризировать ход роста по соснякам Южной Финляндии на момент времени измерений 1916-1918 гг.

Таблица 1

Запас $\hat{V}$ деловой древесины в коре в нормальных сосняках

\begin{tabular}{|c|c|c|c|c|c|}
\hline \multirow{3}{*}{$\begin{array}{c}\text { Возраст } \\
t, \text { лет }\end{array}$} & \multicolumn{5}{|c|}{$\left[3\right.$, c.34-35], $\mathrm{m}^{3} /$} \\
\hline & \multicolumn{5}{|c|}{ Іп лес } \\
\hline & OMT & $\mathrm{MT}$ & VT & $\mathrm{CT}$ & CIT \\
\hline 10 & 19 & 13 & 10 & 7 & \\
\hline 20 & 70 & 60 & 44 & 24 & 3 \\
\hline 30 & 140 & 135 & 87 & 47 & 10 \\
\hline 40 & 08 & 200 & 134 & 75 & 17 \\
\hline 50 & 279 & 260 & 177 & 104 & 31 \\
\hline 60 & 344 & 313 & 219 & 128 & 46 \\
\hline 70 & 405 & 363 & 262 & 153 & 62 \\
\hline 80 & 458 & 407 & 299 & 178 & 80 \\
\hline 90 & 00 & 443 & 328 & 203 & 98 \\
\hline 100 & 535 & 472 & 351 & 222 & 114 \\
\hline 110 & 560 & 492 & 366 & 240 & 132 \\
\hline 120 & 576 & 503 & 375 & 254 & 148 \\
\hline 130 & - & - & 382 & 266 & 164 \\
\hline 140 & - & & 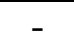 & 275 & 180 \\
\hline 150 & - & - & - & 282 & 195 \\
\hline
\end{tabular}

Пусть типы леса будут независимыми параметрами. Такое допущение принято в лесоведении, создаются разные структурированные классификации. Но это противоречит экологическому закону Коммонера «всё связано со всем». В других статьях докажем зависимость типов леса друг от друга через параметры лесной почвы. Кроме того, примем допущение, что: «В своей динамической типологии леса И.С. Мелехов предлагает уделять основное внимание древостою как основному компоненту (эдификатору) леса и объекту хозяйственного воздействия» [4]. Негласно это как закон давно принят в лесоводстве.

Методика выявления биотехнических закономерностей дана в $[5,6]$. В общем случае она включает три этапа: эвристический, структурный и параметрический.

Идентификация эвристическая. На этом этапе применяются два новых понятия - вейвлет и сигнал. Вейвлет (всплеск) - 
это математическая функция. Английское слово «wavelet» означает «маленькая волна». Вейвлеты - это семейство функций, «волны, идущие друг за другом». Осью абсцисс может быть не только время (в нашем случае возраст сосняков), но и любая физическая величина. Вейвлет имеет четкую амплитудночастотную характеристику (АЧХ) и поэтому может изучаться методами теории колебаний. Но в статье анализа АЧХ по моделям не приводим.

Гармоничный вейвлет любой природы и асимметричной формы имеет вид

$$
y=\sum_{i=1}^{m} y_{i}, y_{i}=A_{i} \cos \left(\pi x / p_{i}-a_{8 i}\right), A_{i}=a_{1 i} x^{a_{2 i}} \exp \left(-a_{3 i} x^{a_{4 i}}\right), p_{i}=a_{5 i}+a_{6 i} x^{a_{7 i}},
$$

где $y$ - показатель (запас кругляка, $\left.\mathrm{m}^{3} / г \mathrm{a}\right), i$ - номер составляющей, $m$ - количество членов (1), $x$ - объясняющая переменная (возраст древостоя, лет), $A$ - амплитуда (половина) вейвлета (ось $y$ ), $p$ - полупериод колебания (ось $x$ ), $a_{1} \ldots a_{8}$ параметры (1), принимающие числовые значения в ходе идентификации вейвлета по исходным данным из таблицы 1.

Физико-математический подход предполагает понимание рядов распределения таблицы 1 как отражений какого-то составного процесса поведения множества из 241 сосняка.

Сигнал - это материальный носитель информации. А информация нами понимается как мера взаимодействия [6]. Сигнал может генерироваться, но его приём не обязателен. Когда 241 сосняк сгруппирован по 5 типам леса и 15 классам возраста, сигнал от каждого древостоя в виде множества деревьев сильно затушевывается. Из книги [3] видно, что при проведении линий вручную на миллиметровке трудно ожидать от «выравнивания» учета всего множества сигналов: всё сделано для упрощения неавтоматизированных расчетов.

Эвристическая идентификация происходит и на структурнопараметрических этапах. Причем априорная информация из [3] существенно дополняется апостериорной информацией, возникающей в ходе моделирования и в последующем анализе составляющих модели (1).

Осмысление результатов расчетов после каждого сеанса вычислений в программной среде CurveExpert дает принципиально новые научнотехнические решения на уровне изобретений. Удивительным является то, что все сигналы типа (1) являются общими для объектов исследования любой природы. Различие состоит только в частных конструкциях из (1).

Идентификация структурная. По принципу «от простого к сложному» были предложены (табл. 2) «кирпичики» для построения, по ходу структурнопараметрической идентификации биотехнического закона, любой конструкции искомой статистической модели.

В таблице 2 показаны все «нормальные» фрагменты, у которых впереди могут быть расположены оперативные константы «+», «-» и др. Шесть устойчивых законов распределения являются частными случаями биотехнического закона, показанного внизу таблицы 2. При моделировании можно идентифицировать устойчивыми законами и закономерностями в двух режимах статистической обработки данных таблицы 1: 
- выявлять только детерминированные нелинейные закономерности;

- дополнить эти закономерности колебательными возмущениями.

Таблица 2

Математические конструкты для построения статистической модели

\begin{tabular}{|l|l|}
\hline $\begin{array}{c}\text { Фрагменты искомой модели без предыстории } \\
\text { изучаемого явления или процесса }\end{array}$ & $\begin{array}{c}\text { Фрагменты искомой модели с предысто- } \\
\text { рией } \\
\text { изучаемого явления или процесса }\end{array}$ \\
\hline $\begin{array}{l}y=a x \text { - закон линейного роста или спада (при } \\
\text { отрицательном знаке перед правой стороной } \\
\text { формулы) }\end{array}$ & $\begin{array}{l}y=a \text { - закон не влияния принятой перемен- } \\
\text { ной на показатель, который имеет предыс- } \\
\text { торию значений }\end{array}$ \\
\hline $\begin{array}{l}y=a x^{b} \text { - закон показательного роста (закон по- } \\
\text { казательной гибели } y=a x^{-b} \text { не является устой- } \\
\text { чивым, из-за бесконечности при нулевом зна- } \\
\text { чении переменной) }\end{array}$ & $\begin{array}{l}\text { логии, Парето в экономике, Мандельброта в } \\
\text { физике) экспоненциального роста или ги- } \\
\text { бели, относительно которого создан метод } \\
\text { операторных исчислений }\end{array}$ \\
\hline $\begin{array}{l}y=a x^{b} \exp (-c x) \text { - биотехнический закон в упро- } \\
\text { щенной форме, т.е. при интенсивности гибели } \\
(\text { спада }) 1\end{array}$ & $\begin{array}{l}y=a \operatorname{exр}\left( \pm c x^{d}\right) \text { - закон экспоненциального } \\
\text { роста или гибели, - по автору статьи }\end{array}$ \\
\hline \multicolumn{2}{|c|}{$y=a x^{b} \exp \left(-c x^{d}\right)$ - биотехнический закон, предложенный проф. П.М. Мазуркиным } \\
\hline
\end{tabular}

Идентификация параметрическая. Она выполнялась в программной среде типа CurveExpert (есть сайт) и этой методологией пользуются студенты и аспиранты. На сквозных примерах методология структурно-параметрической идентификации показана в книге [6].

Прекращение процесса идентификации принимается по условию достижения погрешности измерений. По данным таблицы 1 цена деления значений показателя равна $1 \mathrm{~m}^{3} /$ га. Поэтому моделирование идентификацией устойчивых законов из таблицы 2 может быть продолжено до погрешности $\pm 0,5 \mathrm{~m}^{3} /$ га, а иногда даже меньше.

Уровни адекватности закономерностей. В таблице 3 приведены интервалы изменения коэффициента корреляции как меры адекватности искомой закономерности.

Существующая шкала квантификации тесноты связи между принятыми факторами (нет связи, слабая и сильная связь) является грубой. В лесной науке до сих пор при статистической обработке сплошь и рядом применяется линейная модель. Это исходит из того, что 23-я проблема Гилберта до сих пор не решена, а линейная модель инварианта к любому типу распределения, в том числе и негауссовой структуры, и даже к скедастическим данным с переменной дисперсией. Поэтому нами была предложена для технических экспериментов, где погрешность измерений не превышает 5\%, другая шкала (третий столбец табл. 3). Однако для деревьев и древостоев этого явно недостаточно.

Поэтому для многих природных объектов, в том числе и для деревьев и древостоев, пришлось ввести дополнительно еще два интервала уровня адекватности, что нами было выполнено только при моделировании распределений рядов простых чисел. 
Такая высокая адекватность указывает на высокий уровень проявления закономерности (1) у лесных древостоев и деревьев, причем даже при сильном огрублении в так называемых «таблицах хода роста».

Тип леса ОМТ. По таблице 1 тренд имеет (рис. 1) биотехнический закон в виде

$V=0,25150 t^{1,99997} \exp \left(-0,021142 t^{0,93253}\right)$. $(2)$

Коэффициент корреляции $r=0,99997$ столь высокий, что мож-

Уровни и шкалы тесноты связи у факторов

\begin{tabular}{|c|c|c|c|}
\hline \multirow{2}{*}{$\begin{array}{c}\text { Интервал } \\
\text { коэфф. } \\
\text { коррел. }\end{array}$} & \multicolumn{3}{|c|}{ Шкала тесноты математической связи } \\
\hline & $\begin{array}{l}\text { существ. } \\
\text { классиф. }\end{array}$ & $\begin{array}{c}\text { технических } \\
\text { измерений }\end{array}$ & $\begin{array}{c}\text { прецизионных } \\
\text { измерений }\end{array}$ \\
\hline 1 & \multirow{5}{*}{$\begin{array}{l}\text { сильная } \\
\text { связь }\end{array}$} & однозначная & однозначная \\
\hline $0,99 \ldots 1,00$ & & \multirow{3}{*}{ сильнейшая } & почти однозн. \\
\hline $0,95 \ldots 0,99$ & & & сверхсильная \\
\hline $0,90 \ldots 0,95$ & & & сильнейшая \\
\hline $0,7 \ldots 0,9$ & & сильная & сильная \\
\hline $0,5 \ldots 0,7$ & \multirow{2}{*}{$\begin{array}{l}\text { слабая } \\
\text { связь }\end{array}$} & средняя & средняя \\
\hline $0,3 \ldots 0,5$ & & слабоватая & слабоватая \\
\hline $0,1 \ldots 0,3$ & \multirow{3}{*}{$\begin{array}{l}\text { нет } \\
\text { связи }\end{array}$} & слабая & слабая \\
\hline $0,0 \ldots 0,1$ & & слабейшая & слабейшая \\
\hline 0 & & нет связи & нет связи \\
\hline
\end{tabular}

но бы на этой детерминированной модели и остановиться. На множестве древостоев, без выравнивания значений их параметров, теснота связи была бы меньшей. Но вейвлеты присутствуют всегда, однако лесная наука пока не умеет их понять как сигналы со стороны живых лесов.

Тренд динамики запаса стволовой древесины

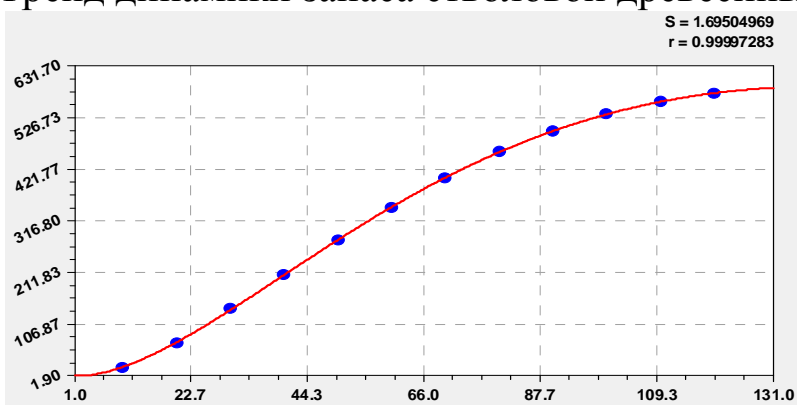

Колебательное возмущение от фенотипа

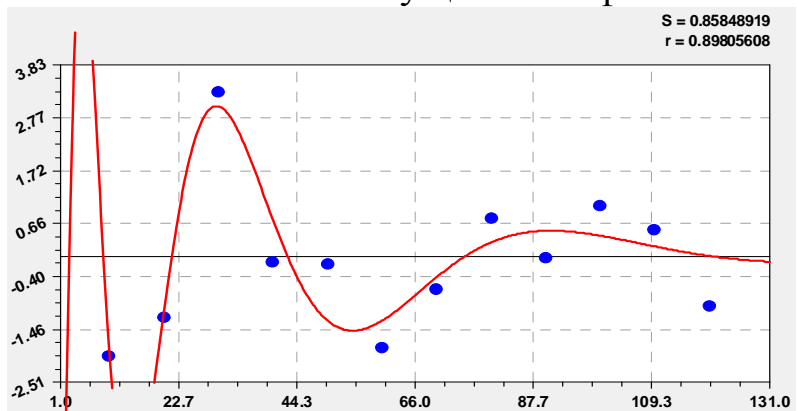

Колебание влияния генотипа + фенотипа

$S=0.20156814$
$r=0.97746369$

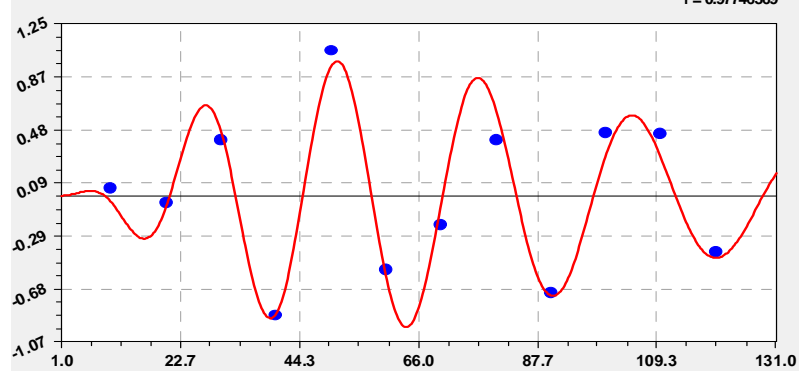

Рис. 1. Динамика запаса древесины в типе леса OMT
Примем гипотезу (время $t$ в годах):

- первая не волновая составляющая трехчленной модели динамики запаса древостоев типа ОМТ в основном характеризует влияние генотипа по биотехническому закону стрессового возбуждения сосняков;

- вейвлет с амплитудой по закону экспоненциальной гибели преимущественно показывает влияние фенотипа (ангармоническое колебание);

- в третьем члене модели (1) генотип + фенотип совместно показывают людям лесной науки асимметричный вейвлет-сигнал с амплитудой по биотехническому закону.

В нормальных естественных лесах Южной Финляндии периода 1916-1918 гг. влияние двух колебаний малое, и коэффициент динамичности $k_{\partial}=(\hat{V}-V) / \hat{V}$, где $V$ - расчетный по модели (табл. 4) запас древесины, - также очень малый. Но в существующих сосняках колебания будут весьма значимыми, что повысит динамичность их поведения.

Тип леса МТ. Модель динамики 
запаса определяется (рис. 2) четырьмя составляющими, из которых первые два вейвлета относятся к преимущественному влиянию фенотипа.

Тренд динамики запаса стволовой древесины

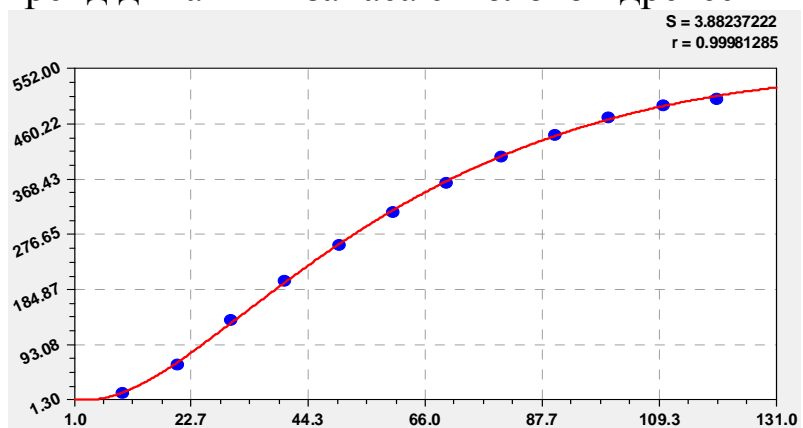

Сквозная волна возмущения от фенотипа

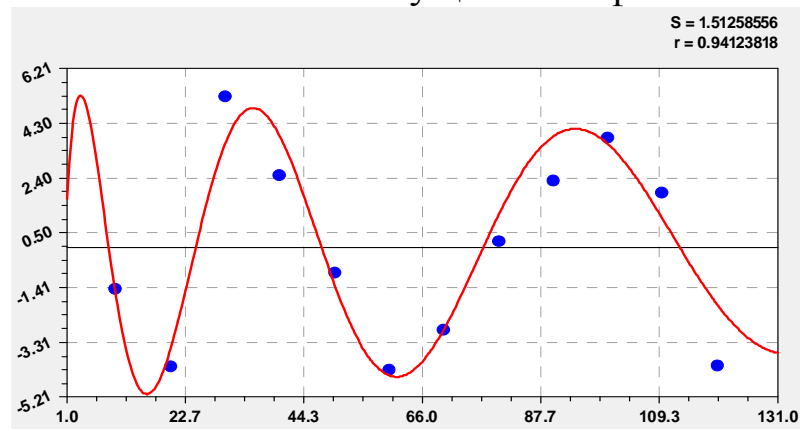

Дополнительное влияние от фенотипа $\mathrm{S}=0.37759222$

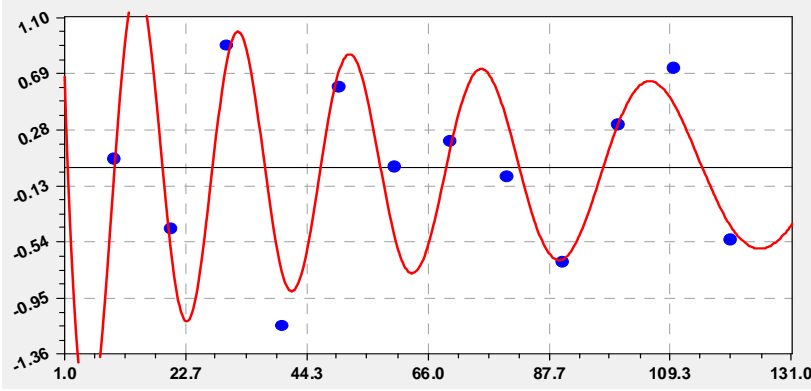

Колебание влияния генотипа + фенотипа $\mathrm{S}=0.07259483$

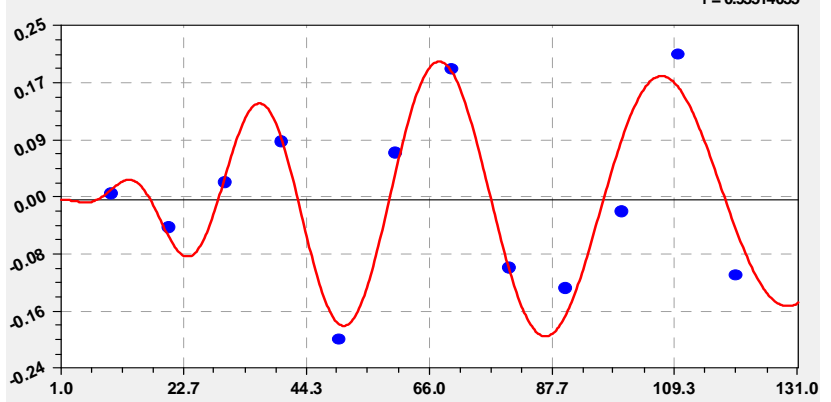

Рис. 2. Динамика запаса в типе леса MT
Тренд динамики запаса стволовой древесины

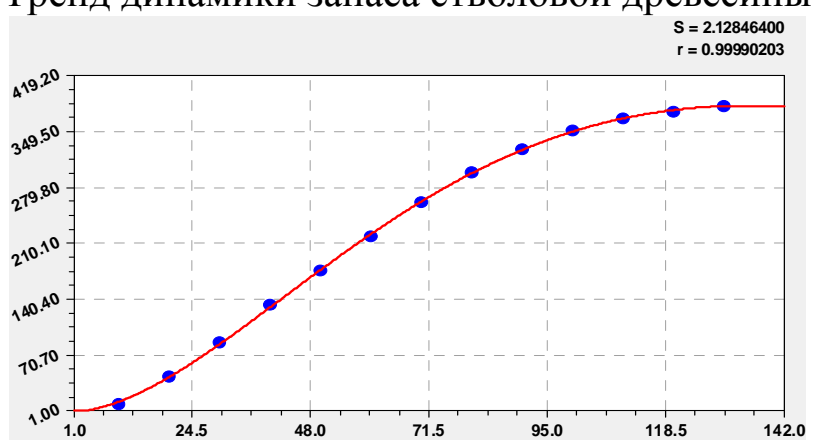

Спадающая волна возмущения от фенотипа $\mathrm{S}=0.85182432$

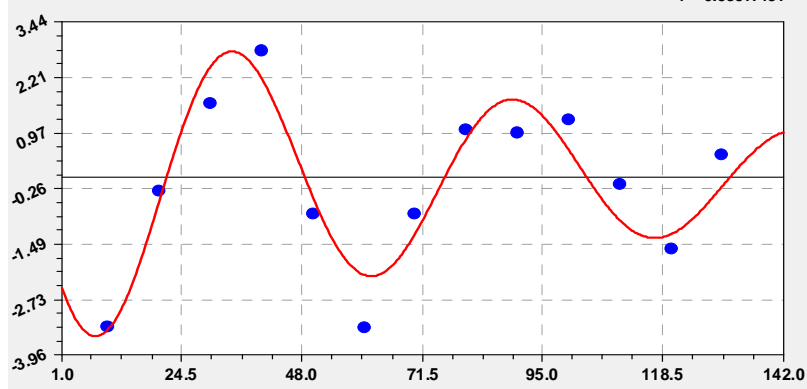

Длинное колебание влияния «генотип + фенотиП»

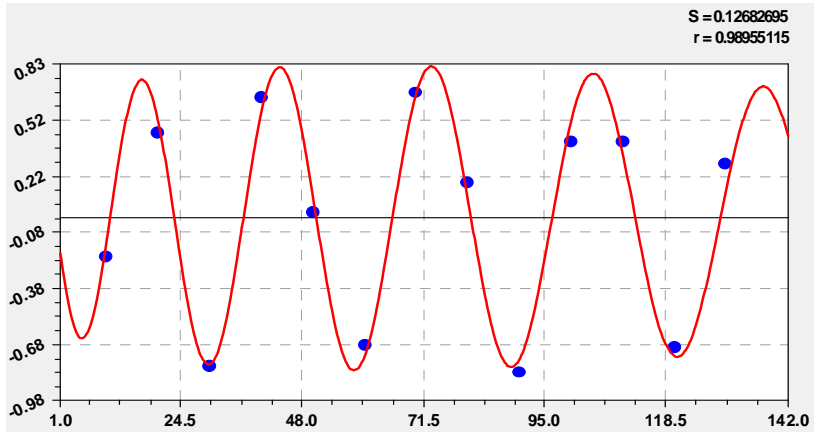

Рис. 3. Динамика запаса в типе леса VT

Сравнение показывает, что ухудшение почвенных условий при переходе сосняка от типа ОМТ (рис. 1) к типу MT (рис. 2) дает повышение у первой волны, преимущественного влияния фенотипа, увеличение амплитуды почти в два раза. В обоих случаях период колебания повышается (частота возмущения сосняка снижается). Но в типе леса МТ амплитуда и частота колебательного возмущения уменьшаются намного медленнее по сравнению с типом леса OMT. К 120 годам тип леса ОМТ получает почти нулевую амплитуду колебания, и тип МТ по формуле продолжает возмущаться до 250 и более лет.

При этом тип леса МТ имеет две волны влияния фенотипа. 
Tип леса VT. Как и в типе ОМТ, здесь модель динамики определяется (рис. 3) биотехническим законом и только двумя волнами колебательного возмущения. Но влияние фенотипа с одной волной похоже на тип МТ, а совместное влияние генотипа и фенотипа в типе леса VT гораздо длиннее по времени проявления. Различия видны по параметрам модели (1).

Тип леса СТ. Здесь (рис. 4) имеется очень длинная волна возмущения от фенотипа. Но совместное влияние «генотип + фенотип» дается двумя ангармоническими волнами.

Тренд динамики запаса стволовой древесины

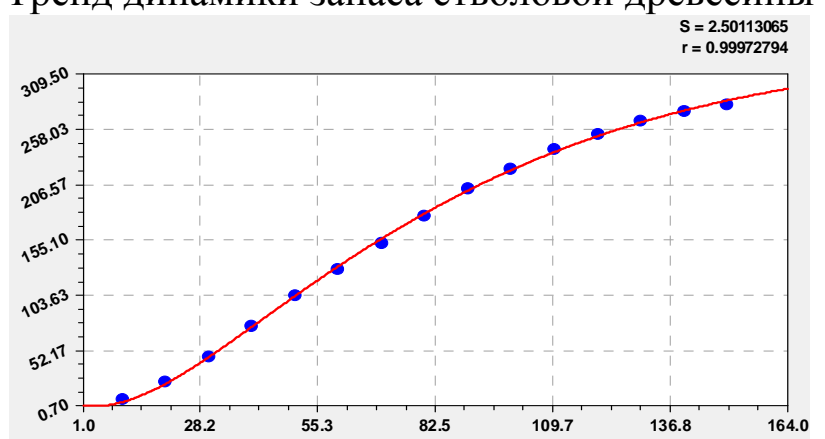

Сквозная волна возмущения от фенотипа

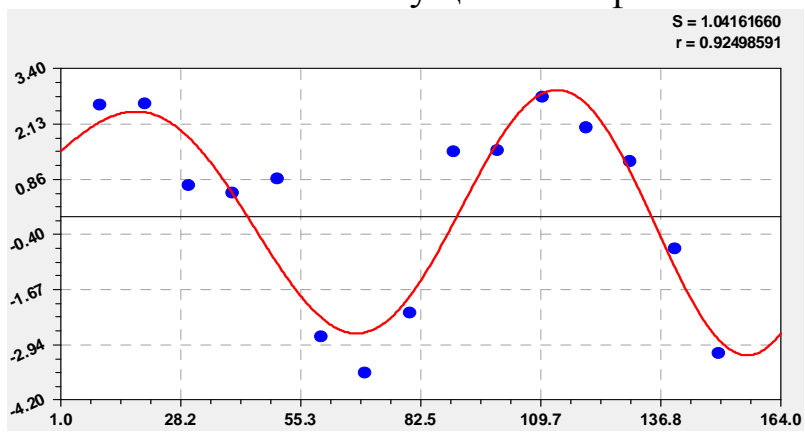

Колебание влияния генотипа + фенотипа

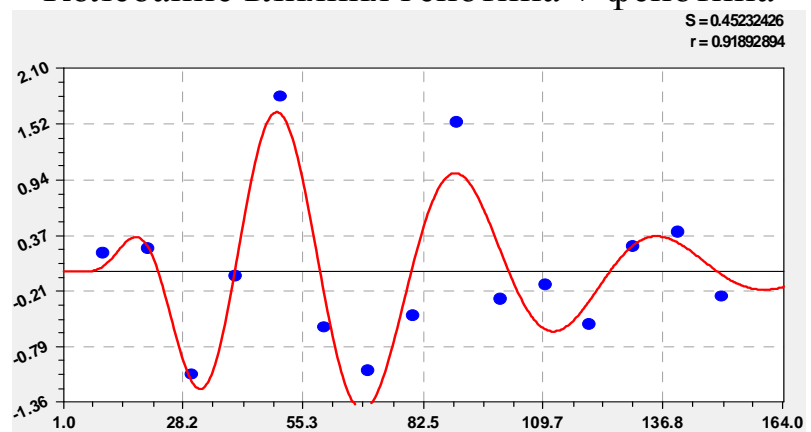

Четвертая составляющая закономерности

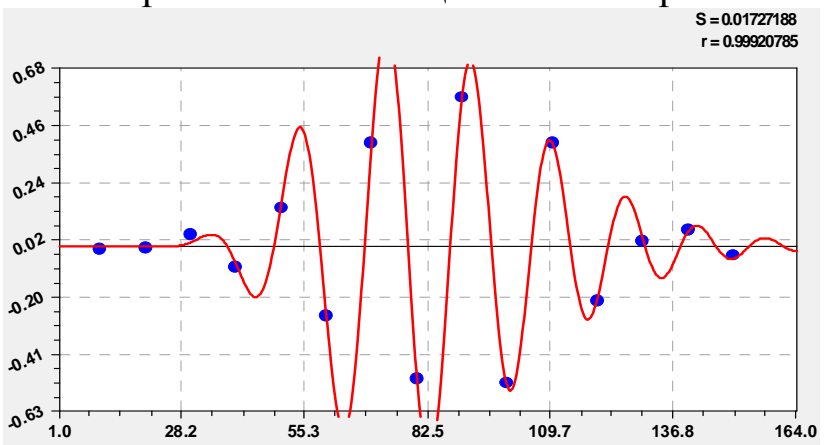

Рис. 4. Динамика запаса древесины в типе СТ

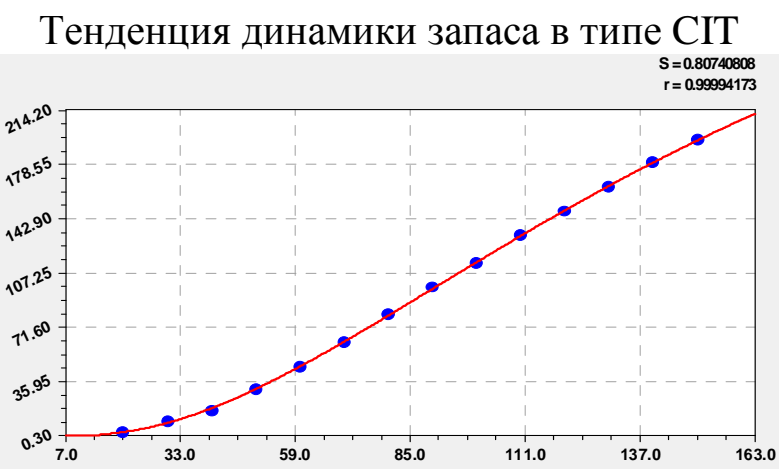

Волна возмущения в возрасте 15-70 лет

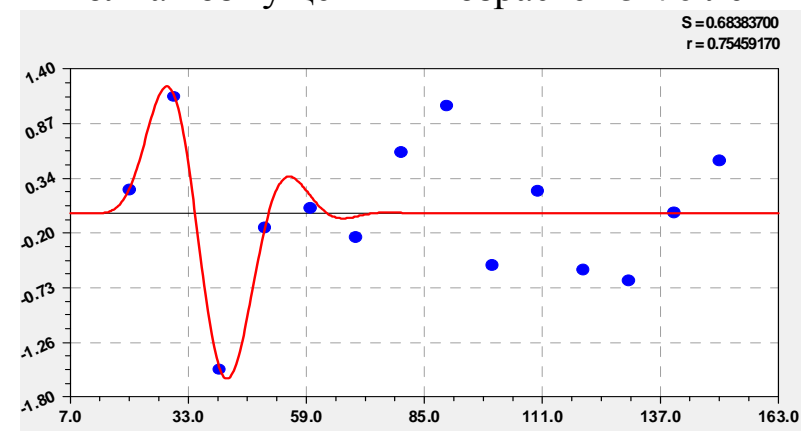

Волна возмущения в возрасте 40-140 лет

$\mathrm{S}=0.43818042$

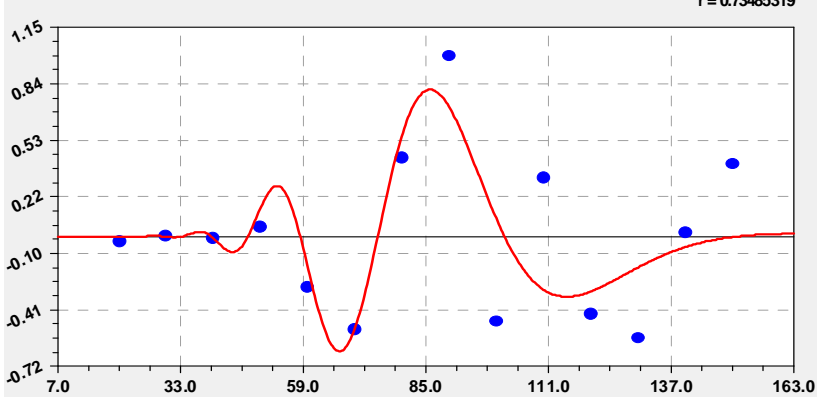

Волна возмущения в возрасте 60-165 лет

$\mathrm{S}=0.04551267$

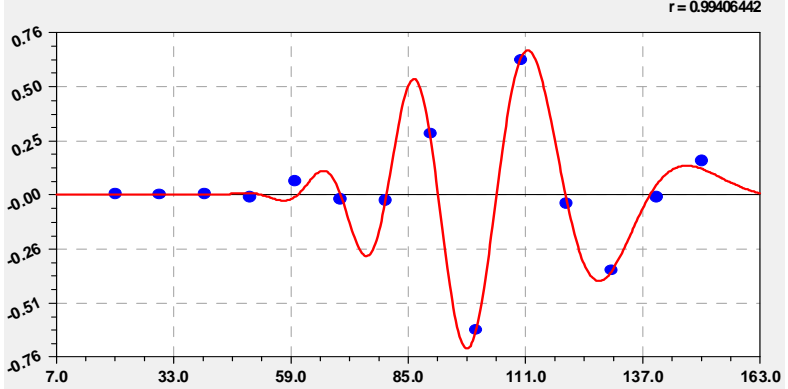

Рис. 5. Колебательная адаптации сосняков к типу леса CIT 
Тип леса CIT. На рисунке 5 показаны графики четырех членов, из которых нет чистого влияния фенотипа, а все три ангармонические волны происходят в разные периоды времени. Самой опасной для культурных сосняков является волна возмущения в возрасте 15-70 лет. Но мы знаем [5], что есть еще опаснее волны возмущения в период молодняков 0-30 лет.

Результаты измерений запаса древостоев по 241 пробной площади можно было не группировать по десятилетиям, а сразу же поместить в таблицу 1 исходных данных (программная среда CurveExpert позволяет до 3500 строк).

Эта же биотехническая функция (1) в общем виде подходит и для распределения 203 дерева в разновозрастном сосняке [5] в возрасте 60...464 лет. Если в среднем для каждой пробной площади измеряются до 10 модельных деревьев, то в общую таблицу исходных данных можно поместить до 24 таксационных показателей.

По измеренным деревьям для 241 пробной площади было бы 2410 строк.

Результаты моделирования всех данных из таблицы 1 сведены в таблицу 4.

Таблица 4

Параметры общего волнового уравнения (1) $V=f(t)$ при пяти типах сосняков

\begin{tabular}{|c|c|c|c|c|c|c|c|c|c|}
\hline \multirow{2}{*}{$\begin{array}{l}\text { Тип } \\
\text { леса }\end{array}$} & \multicolumn{4}{|c|}{ Амплитуда колебания } & \multicolumn{4}{|c|}{ Полупериод и сдвиг колебания } & \multirow{2}{*}{$\begin{array}{l}\text { Коэфф. } \\
\text { коррел. }\end{array}$} \\
\hline & $a_{1 i}$ & $\overrightarrow{a_{2 i}}$ & $a_{3 i}$ & $a_{4 i}$ & $a_{5 i}$ & $a_{6 i}$ & $a_{7 i}$ & $a_{8 i}$ & \\
\hline \multirow{3}{*}{ OMT } & 0,27254 & 1,95633 & 0,015356 & 0,98431 & 0 & 0 & 0 & 0 & \multirow{3}{*}{1,00000} \\
\hline & $-5,42572$ & 0 & 0,023707 & 1 & 0,66174 & 0,87216 & 0,65736 & 1,47834 & \\
\hline & 0,0022712 & 2,30622 & 0,14696 & 76428 & 10,23227 & 0,00021006 & 1,91686 & 2,81154 & \\
\hline \multirow{4}{*}{ MT } & $2.24895 \mathrm{e} 9$ & 8.30053 & 27.28964 & 0.14664 & 0 & 0 & 0 & 0 & \multirow{3}{*}{1,00000} \\
\hline & $-9,02507$ & 0 & 0,00038759 & 1 & $-0,21448$ & 0,16640 & 0,83886 & 0,73183 & \\
\hline & 68975843,0 & 0 & 15,16482 & 0,049166 & 5,28659 & 0,0012142 & 1,61024 & 3,76489 & \\
\hline & 0,00016170 & 3,60307 & 1,31633 & 0,43051 & 2,37620 & 1,57291 & 0,42628 & 5,35522 & 4 \\
\hline \multirow{3}{*}{ VT } & 0,20025 & 1,85714 & 0,0045874 & 1,18732 & 0 & 0 & 0 & 0 & \multirow{2}{*}{0,999} \\
\hline & $-3,42204$ & 0 & 0,0059615 & 1 & 24,46745 & 0,00056725 & 1,77849 & 1,29151 & \\
\hline & 0,53331 & 0,11914 & $2,01556 \mathrm{e}-5$ & 1,95486 & 6,92321 & 1,97220 & 0,27218 & $-1,57557$ & 0,98 \\
\hline \multirow{4}{*}{ CT } & $1,98863 \mathrm{e} 9$ & 7,59128 & \begin{tabular}{|l|}
27,59668 \\
\end{tabular} & 0,13323 & 0 & 0 & 0 & 0 & \multirow{3}{*}{$1,($} \\
\hline & 3,53736 & 0 & 0,0025852 & 1 & 284,2839 & $-205,4737$ & 0,027016 & 0,99237 & \\
\hline & $1,40789 \mathrm{e}-6$ & 8,78429 & 3,87880 & 0,42319 & $-7,59107$ & 7,75602 & 0,23669 & 0,33937 & \\
\hline & $4,91688 \mathrm{e}-19$ & 13,75762 & 0,61345 & 0,77501 & 11,46863 & $-0,0067788$ & 1,14197 & 2,96414 & 0,99921 \\
\hline \multirow{4}{*}{ CIT } & 29029622,0 & 8,85952 & 28,22672 & 0,13780 & 0 & 0 & 0 & 0 & \multirow{4}{*}{0,99999} \\
\hline & $-1,99854 \mathrm{e}-26$ & 23,48626 & 0,66358 & 0,99997 & 0,79151 & 0,10716 & 1,00016 & 0,34810 & \\
\hline & $3,03366 \mathrm{e}-25$ & 24,72273 & 7,13885 & 0,45359 & 0,098 & 0,020024 & 0,99268 & 2,29805 & \\
\hline & $1,48309 \mathrm{e}-38$ & 24,83145 & 0,47025 & 0,88397 & 6,523 & 0009353 & 1,65044 & $-3,924$ & \\
\hline
\end{tabular}

По отрицательному знаку перед составляющими видно, что преимущественное влияние фенотипа в типах леса ОМТ, МТ и VT имеет кризисный для запаса характер. А для типа леса СТ влияние фенотипа позитивное, но при этом полупериод -205,4737 лет имеет убывающий характер. Аналогично входит в тремор и четвертая составляющая модели СТ. Для типа леса СІT все три волны имеют выпуклую амплитуду, но при этом первая волна является кризисной. Начальный период в возрасте $t=0$ лет равен $2 p=2 a_{5}$ (табл. 5). 
Эвристика пятого параметра (1)

\begin{tabular}{|c|c|c|c|}
\hline Тип & $a_{5 i}$ & Период & Примечание \\
\hline \multirow{3}{*}{ OMT } & 0 & 0 & $V_{\max }=589 \mathrm{~m}^{3} /$ га, $t^{*}=140$ лет \\
\hline & 0,662 & $2 \times 0,7$ & Два вегетационных сезона \\
\hline & 10,23 & 20,5 & Оборот ядра Солнца (min) \\
\hline \multirow{4}{*}{ MT } & 0 & 0 & $V_{\max }=509 \mathrm{~m}^{3} / г \mathrm{a}, t^{*}=145$ лет \\
\hline & $-0,214$ & $-0,43$ & Период проращивания семян \\
\hline & 9,29 & 18,6 & Цикл 19 летний Луны \\
\hline & 2,38 & 4,8 & $\begin{array}{c}\text { Цикл активного плодоноше- } \\
\text { ния }\end{array}$ \\
\hline \multirow{3}{*}{ VT } & 0 & 0 & $V_{\max }=384 \mathrm{~m}^{3} / \Gamma \mathrm{a}, t^{*}=136$ лет \\
\hline & 24,47 & 48,9 & Два цикла ядра Солнца (max) \\
\hline & 6,92 & 13,8 & Цикл солнечной активности \\
\hline \multirow{4}{*}{ CT } & 0 & 0 & $V_{\max }=312 \mathrm{~m}^{3} /$ га, $t^{*}=231$ год \\
\hline & 284,3 & $2 \times 284$ & Микро ледниковый период \\
\hline & $-7,59$ & 15,2 & $\begin{array}{l}\text { Цикл солнечной активн. } \\
(\max )\end{array}$ \\
\hline & 11,47 & 22,9 & Оборот ядра Солнца \\
\hline \multirow{4}{*}{ CIT } & 0 & 0 & $V_{\max }=335 \mathrm{~m}^{3} /$ га, $t^{*}=393$ лет \\
\hline & 0,79 & $2 \times 0,8$ & Два сезона тепла атмосферы \\
\hline & 0,099 & 0,2 & Двухмесячный лунный цикл \\
\hline & 6,52 & 13,0 & ЦИикл солнечной активности \\
\hline
\end{tabular}

Высокая адекватность биотехнической функции (1) дает проводить эвристическую идентификацию многим значениям параметров модели из данных таблицы 4.

Выводы. Тогда получается, что для любого типа леса применима формула (1), причем со многими поколениями сосен [5].

Таким образом, группировка результатов таксационных измерений по классам возраста (аналогично по ступеням толщины, классам высоты и пр.) - это дань ручной технологии выравнивания кривых на миллиметровой бумаге. Поэтому для выявления устойчивых закономерностей лучше всего принять первичные данные из журналов измерений по каждому дереву на каждой пробной площади. Именно таксация дерева (дендрометрия) будет в ближайшем будущем востребована в любой отрасли лесной науки. Нами было доказано [5, 6], что поведение биологических объектов происходит с колебательным возмущением. Будет ли такое возмущение наблюдаться в сильно выровненных по группам 10 лет, причем по типу леса, данных таблицы 1? Ответ дан положительный.

На рисунках даны две-три волны колебательной адаптации сосняков с возрастом к почве. Есть волновые составляющие в виде вейвлет-сигналов, но их нужно бы выявлять по не выровненным данным, то есть по каждому лесному участку и, в идеале, по каждому учетной (без разрушения) сосне на этом лесном участке.

По формулам (были показаны по пяти типам леса в таблице 4) можно выдвинуть следующую гипотезу о возрастном влиянии на запас стволовой древесины у сосняков:

- 1-ая составляющая - это больше всего отражение генотипа сосны;

- 2-й и 3-й член - это преимущественно отражение фенотипа по долговременной закономерности с амплитудой в виде закона гибели (спада), причем в типе леса CIT он становится относительно коротким по продолжительности ангармоническим колебанием;

- 3, 4 и последующие ангармонические колебания с короткопериодической амплитудой показывают совместное влияние генотипа и фенотипа в сосняке любого типа. 
Эту гипотезу вполне можно подтверждать по первичным данным разных таксационных измерений. Поэтому главная рекомендация - не группируйте данные своих измерений, публикуйте таблицы исходных данных своих экспериментов без всякой группировки.

\section{Литература}

1. Динамическая типология леса // http://lesnyepozhary.ru/tipologiya-lesa/ dinamicheskaya-tipologiya-lesa.html (Дата обращения 16.03.2013).

2. Лесная типология в в Финляндии // http://lesnyepozhary.ru/tipologiyalesa/lesnaya -tipologiya-v-finlyandii.html (дата обращения 16.03.2013).

3. Каяндер А.К. І. Сущность и значение типов леса. II. Различие в учениях о типах леса (Каяндера, Морозова и Сукачева). М.: Гослестехиздат, 1933. 50 с.

4. Концепция динамической типологии И.С. Мелехова (часть 1) // http://allyears.ru/ lesovedenie/1177-koncepciya-dinamicheskoy-tipologii-i-smelehova-chast-1.html (дата обращения 16.03.2013).

5. Мазуркин П.М. Дендрохронологические шкалы разновозрастного сосняка // Современные наукоемкие технологии. №6. 2010. С.32-44.

6. Мазуркин П. М., Михайлова С.И. Территориальное экологическое равновесие = Territprial ecological balance: аналит. обзор; Учреждение Рос. акад. наук Гос. публич. науч.-техн. б-ка Сиб. отд-ния РАН, М-во образования и науки Рос. Федерации Федер. Марийс. гос. техн. ун-т. Новосибирск: ГПНТБ СО РАН, 2010. 430 с. (Сер. Экология. Вып. 94).

7. Математические методы в лесной типологии // http://lesnyepozhary.ru/tipologiya-lesa/matematicheskie-metody-v-lesnojtipologii.html (дата обращения 16.03.2013).

8. Мелехов И.С. Очерк развития наук о лесе в России // http://www.booksite.ru/ fulltext/mel/eho/voc/3.htm (Дата обращения 16.03.2013). 